\title{
RESPONSE OF POSIDONIA OCEANICA PLANTS TO WAVE MOTION IN SHALLOW-WATERS - PRELIMINARY EXPERIMENTAL RESULTS
}

\author{
Luca Cavallaro', Carlo Lo Re ${ }^{2}$, Giovanni Paratore ${ }^{3,4}$, Antonino Viviano ${ }^{4}$ and Enrico Foti ${ }^{4}$
}

\begin{abstract}
Aim of the present work is to contribute to the knowledge about the interaction between the flow induced by waves and the aquatic vegetation. More in details, the results of preliminary tests of an experimental laboratory investigation about the response of a Posidonia Oceanica meadow to wave motion in shallow waters is reported. A wide attention was posed to the behavior of a synthetic plants with plastic material. To this aim an image acquisition technique was used to analyze and compare the movement of both the artificial plant and the real one. The experiments carried out about the interaction between the artificial meadow and the waves showed a significant wave dumping, in particular in the case of plants having the same length of the water depth.
\end{abstract}

Keywords: Posidonia Oceanica; canopy; wave; drag force; wave damping

\section{INTRODUCTION}

The aquatic vegetation causes important effects on the coastal hydrodynamics, especially in the shallow waters where the length of plants is comparable with the water depth. However, the interaction between vegetation and flow is not clear up to now, indeed it represents a big uncertainty, especially when applied into a wave propagation model.

The Posidonia Oceanica (see Fig. 1) is one of the most common marine plant in the Mediterranean sea; usually it is located in sandy bottoms, at depths from 1 $\div 40$ meters, according to water clarity. The plant is composed by a root, called rhizome and characterized by a shape of a short stem, and leaves. The rhizome can grows in vertical and horizontal direction. Such a characteristic of the root allows to the plant to anchor itself to the sandy bottom and, at the same time, to contrast the gradual silting due to the continuous sediment storage between the long leaves. In presence of a sandy bottom, the netting of the perpendicular rhizomes creates a strong zone, called mattes. Such a peculiarity enables the sandy bottom stabilization, being this aspect particularly important in regions affected by coastal erosion.

The leaves are ribbon-like and extremely flexible, they are characterized by width of $1 \mathrm{~cm}$ and a length up to $1.5 \mathrm{~m}$; they are arranged in tufts, each usually composed by six leaves, with age and length decreasing from outside to inside. Posidonia Oceanica is present on rocky bottom rarely. Moreover the density of plants usually varies between 500 and 1,000 plants per square meter (Koch, 2006).

A peculiar characteristic of such a plant, as other species of marine vegetation, is to represent a variable hydraulic roughness, since as the flow velocity increases the leaves bend more and more, until they lie on the bottom. Therefore the "roughness" has to be seen as a function of the flow conditions (velocity and depth of the marine current). Of course, the effects of such a roughness are especially marked in lagoons, characterized by large expanses with low depths of the order of one meter.

In presence of waves the flow becomes periodic, and the leaves follows the movements of the flow, keeping quite similar oscillatory movements, and the effects that the plants have on the flow (vertical velocity distribution, turbulence, energy dissipation) become complex to be identified.

On such a topic several studies have been performed, even if they focused the attention mainly on the steady flow. Indeed, recently the interaction between flexible plants and steady flow has been studied by Ghisalberti and Nepf $(2002,2005,2006)$, Ciraolo et al. $(2006,2008)$ e Ciraolo e Ferreri (2007). The interaction between rigid vegetation and wave was analyzed by Lowe et al. (2005), while Bradley e Houser (2009) e Augustin et al. (2009) have posed their attention on the wave attenuation with flexible plants and wave motion, obtaining a significant wave height reduction.

The present work aims at gathering information about the interaction between vegetation and wave flow by means of an experimental investigation in laboratory. The paper is organized into five paragraphs: after the introduction, the experimental apparatus used for the experiment is described; then some studies for creating the artificial plant are shown; the fourth paragraph deals with some preliminary results; finally some comments are provided and some conclusion are drawn.

\footnotetext{
${ }^{1}$ Department of Civil Engineering, University of Messina, Contrada di Dio, Messina, 98166, Italy

${ }^{2}$ Department of Hydraulic Eng. and Environ. Appl., University of Palermo, Viale delle scienze ed.8, Palermo, 90128, Italy

${ }^{3}$ Department of Mechanics \& Materials, University of Reggio Calabria, Loc.Feo di Vito, Reggio Calabria, 89060, Italy

${ }^{4}$ Department of Civil and Environmental Engineering, University of Catania, viale A. Doria n.6, Catania, 95125, Italy
} 

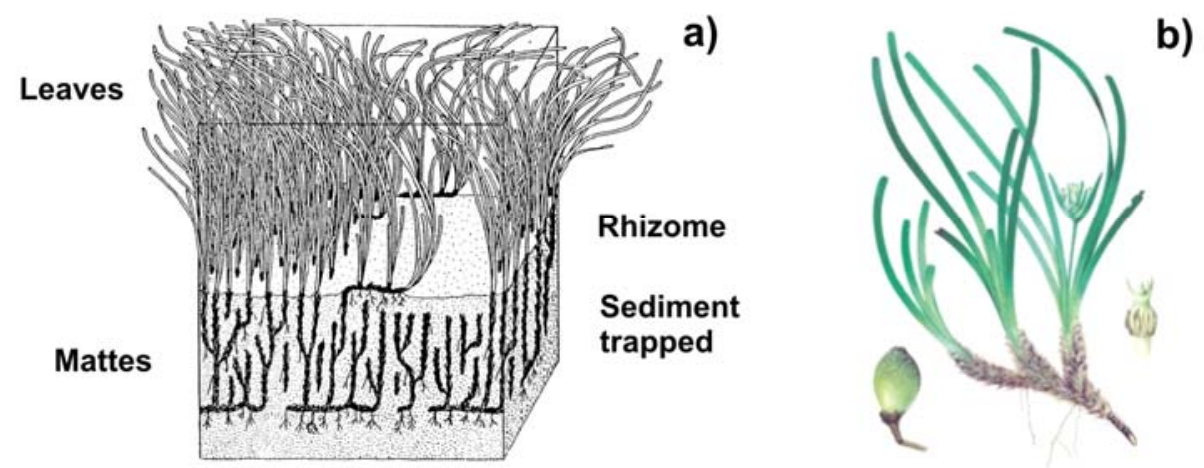

Figure 1. Posidonia Oceanica: a) meadow (after Boudouresque and Meinesz, 1982); b) plant sketch with fruit and flower (after Ciraolo and Ferreri, 2007).

\section{EXPERIMENTAL APPARATUS}

In order to analyze the effects of flexible vegetation on the flow induced by waves, laboratory tests have been performed in a wave flume at the Hydraulic Laboratory of the University of Catania. The wave flume, shown in Fig. 2, is about $9.00 \mathrm{~m}$ long, $0.50 \mathrm{~m}$ wide and $0.70 \mathrm{~m}$ high. It has lateral glass walls. Regular waves are obtained by means of a piston type wavemaker, located at one end of the wave flume, and driven by an electrical motor. To reduce the effects of wave reflection from the paddle a filter has been placed closed to the wavemaker. Moreover an artificial absorbing beach, constituted of gravels, has been realized at the opposed side with respect to the wavemaker, with a slope equal to $1: 10$.

The wave flume is equipped with a measurement system constituted by resistive probes and an Acoustic Doppler Velocimeter (ADV) to measure the flow velocity in the water column.

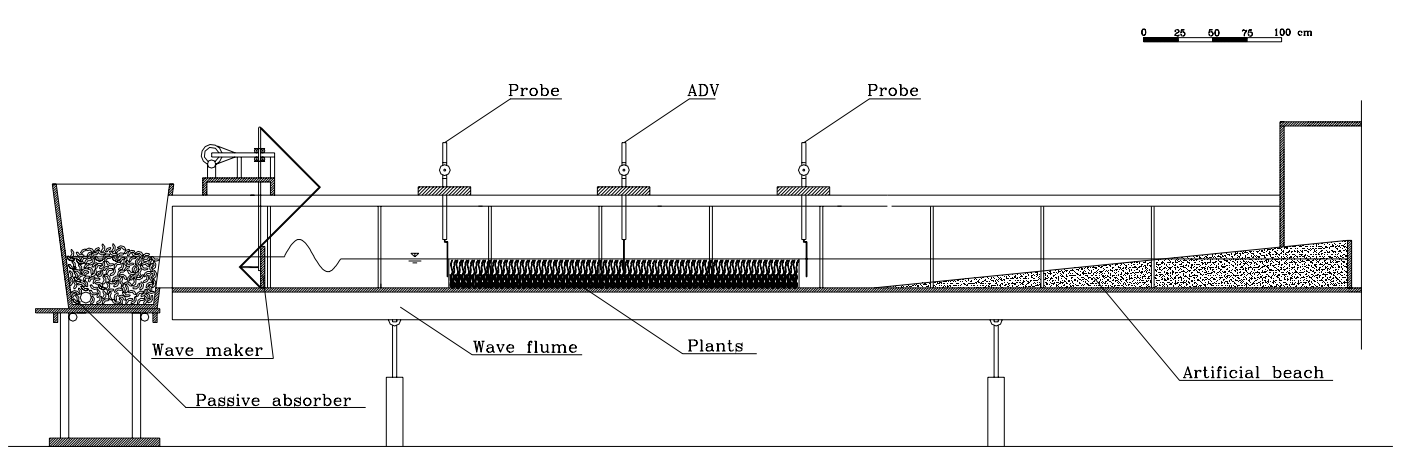

Figure 2. Lateral view of the adopted wave flume at the Hydraulic Laboratory of the University of Catania.

Inside the wave flume, a synthetic meadow, with a length of $2.5 \mathrm{~m}$, has been realized at a distance of $1.40 \mathrm{~m}$ from the wavemaker. The density of such an artificial meadow is of 1,024 tufts for square meter. Two resistive probes have been placed at the boundaries of the meadow, at distances respectively equals to $1.30 \mathrm{~m}$ e $2.90 \mathrm{~m}$ from the paddle of the wavemaker.

The position of the ADV was chosen as a result of a careful analysis of the flow along the wave flume. More in details, a preliminary flow analysis has been carried out without plants; in such a test the velocity along the wave propagation direction $(\mathrm{u})$ has been measured at a depth of $13 \mathrm{~cm}$, by varying the horizontal displacement of the ADV. The test was performed with waves characterized by an height equal to $4.5 \mathrm{~cm}$ and a period equal to $0.74 \mathrm{~s}$. As shown in Fig. 3, the horizontal mean velocity does not change appreciably along the $\mathrm{x}$ direction in the region where the bottom is horizontal, i.e. up 
to $\mathrm{x}=3.90 \mathrm{~m}$. For such a reason in all the performed tests the ADV has been placed in the correspondence of the mean section of the canopy, i.e. at $x=2.65 \mathrm{~m}$.

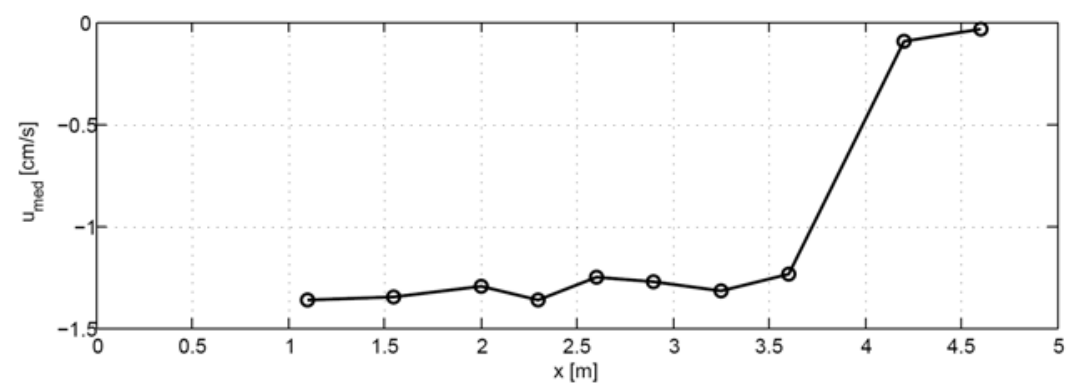

Figure 3. Horizontal mean velocity at $13 \mathrm{~cm}$ depth distribution along the $x$ axis. $(H=4.5 \mathrm{~cm}, \mathrm{~T}=0.74 \mathrm{~s})$.

\section{ARTIFICIAL PLANT}

In order to study the hydrodynamic effects due to the Posidonia Oceanica plants, artificial elements has been chosen to use in the proposed experiments. The chosen material to reproduce the leaves is a low density polyethylene, because of its cost, modeling easiness, and its features (i.e. density) close to the real leaves.

In order to validate the adopted choice, several preliminary tests have been performed to evaluate some macroscopic physical properties of such arbitral vegetation.

A couple of real plants were taken from a beach close to a Posidonia Oceanica meadow, immediately after a storm. As shown in Fig. 4, the plant leaves always grow in 3-4 pairs of similar length and they have a constant width of $1 \mathrm{~cm}$. Moreover, the maximum leaf length is about $22 \mathrm{~cm}$.

The firsts experimental tests were performed in order to compare the buoyancy of artificial and natural leaves. The polyethylene density $\left(0.98 \mathrm{~kg} / \mathrm{dm}^{3}\right)$ is close to the freshwater one as the real leaves density is close to the salt water one. The artificial leaves used for these tests had a thickness of $0.16 \mathrm{~mm}$ and $0.08 \mathrm{~mm}$. The performed tests suggest that the most suitable thickness of the synthetic tape for reproducing the real plant movement into the salt water was $0.08 \mathrm{~mm}$; indeed, the $0.08 \mathrm{~mm}$ thickness artificial leaves show a flotation effect in freshwater similar to the corresponding effect of real leaves into salt water.

Other tests were performed to analyze the plant flexibility. The real and the artificial plants have been anchored to the bottom of a flume where a steady flow has been reproduced (see Fig. 5). The leaves were subjected to a current having a mean velocity equal to $10.8 \mathrm{~cm} / \mathrm{s}$; by acquiring the position of the leaves through a digital camera, a direct comparison of natural and artificial plant flexibility has been carried out. Another test on the plant flexibility was carried out in presence of an oscillatory flow motion as well, with a water depth of $21 \mathrm{~cm}$, and a flow forced by waves characterized by an height of $4.26 \mathrm{~cm}$ and a period of $0.77 \mathrm{~s}$. In both cases the synthetic tufts have showed a general response very similar to the real one.

The following test was performed with a single plant in order to evaluate the artificial plant behaviour into the oscillatory flow induced by waves. The synthetic tufts was placed onto a perforated steel plate. Such a plate was located in the middle of the experimental apparatus shown at the previous section. Monochromatic waves with an height $\mathrm{H}=4.26 \mathrm{~cm}$ and a period of $\mathrm{T}=0.77 \mathrm{~s}$ were produced on a water depth $\mathrm{h}=21 \mathrm{~cm}$. The apices of the artificial plant leaves were marked with a black color (see Fig. 6); such a color is easily to distinguish with the image analysis technique. The leaves trajectories were detected from the acquired frame. In particular, it has been shown that the plants tend to bend in the wave direction propagation. Indeed, in Fig. 7 it is possible to observe that the elliptical orbits traced by the top of the leaves are inclined in the same direction of the wave motion (from the right to the left).

The leaves apices movements analysis gave another positive confirmation on the behavior of the artificial plant in comparison to the real one. 


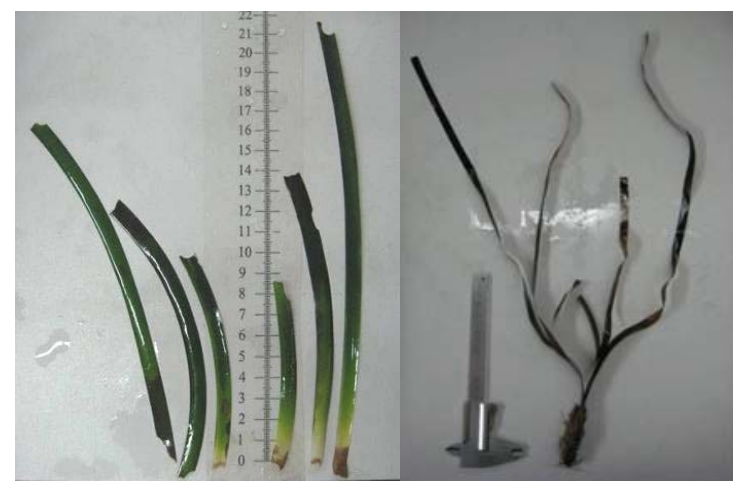

Figure 4. Actual Posidonia oceanica plant used for the experiments in order to test the artificial plant response.

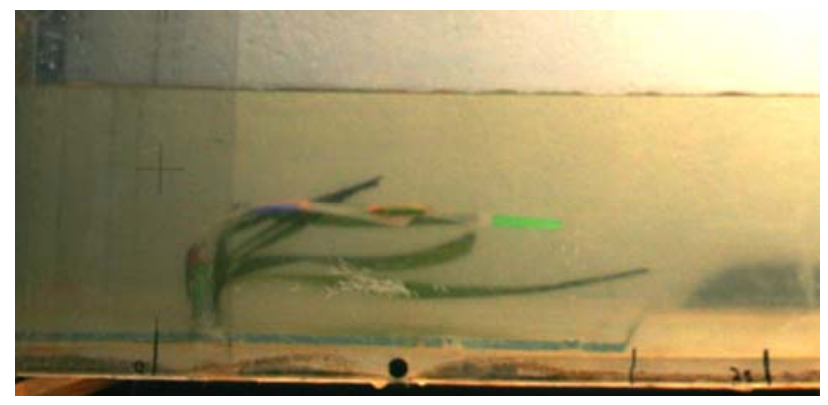

Figure 5. Comparison between the real and artificial plant behaviour as generated by the same current flow.

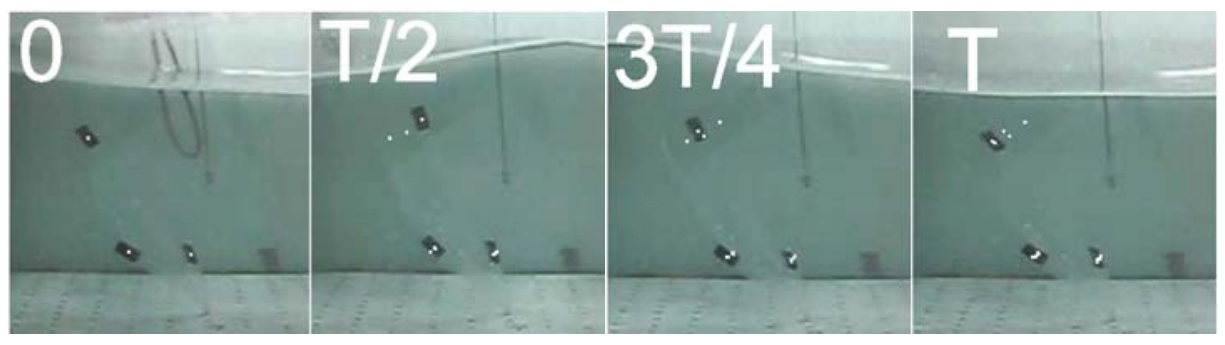

Figure 6. Displacement of artificial Posidonia Oceanica leaves within a wave period

\section{ANALYSIS OF RESULTS}

The study of the interaction between waves and vegetation requires a careful analysis of the mutual effects between the flow induced by waves and the leaves which form the canopy. In such a framework it is useful to analyze the modifications in the flow due to the presence of plants by measuring the velocity profile and the wave characteristics.

In particular, the results of two different sets of experiments are presented: the former is focused on the evaluation of the change in velocity profile induced by the presence of the canopies; the latter is related to the study of wave damping due to canopies.

As regards the first set of experiments, some tests were performed in order to estimate the velocity variation along the water column, related to the presence of canopy. The results were compared with the ones obtained in the same experimental apparatus without vegetation. In particular, Fig. 8 shows the maximum and average velocities profiles, obtained from the gathered data. The same figure shows the corresponding curves of the maximum, minimum and average velocities derived from the linear wave theory. Such curves were shifted towards the negative direction of the horizontal axis of an amount equal to the undertow current (Dean and Dalrymple, 1992). Indeed, it is well known that such 
a current goes in the opposite direction with respect to the wave propagation, in order to take into account of the beach presence in the wave induced flow.

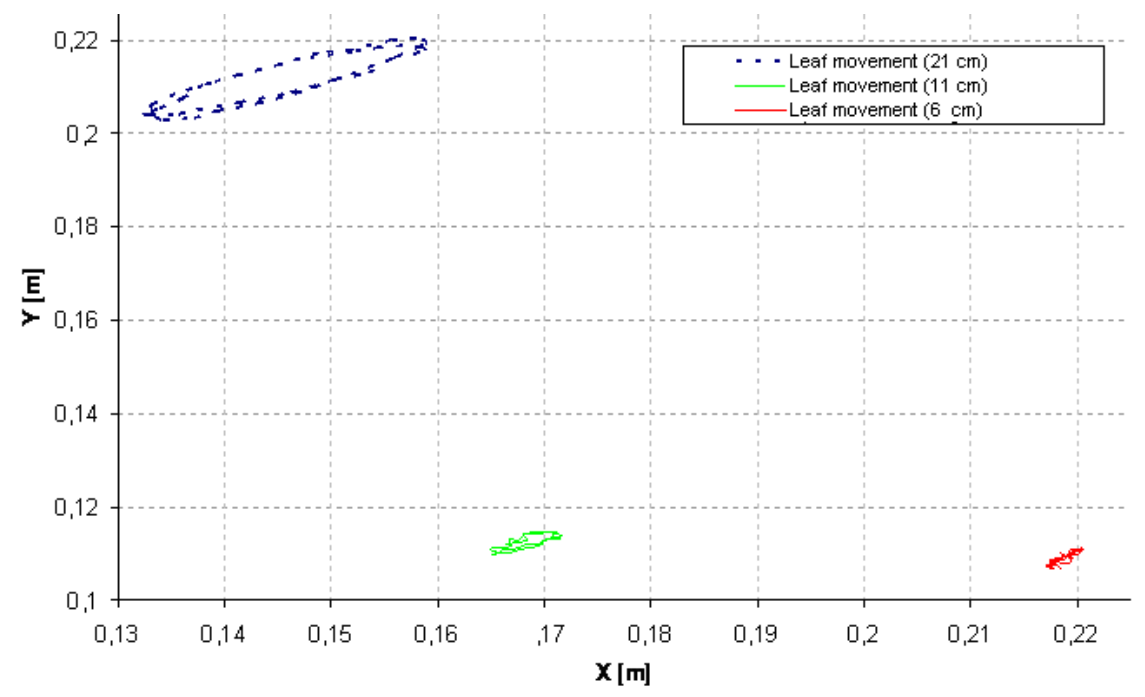

Figure 7. Artificial plant leaves apices displacements as obtained by means of the image analysis technique.

In all the four cases analyzed in Fig. 8, the relative velocities are very close to those estimated using the linear wave theory, independently from the presence of vegetation. It is important to stress that the wave height used to calculate the velocity profiles with the linear wave theory was considered equal to the average between the wave height measured at the two extreme of the meadow. Therefore the presence of vegetation causes a significant energy reduction, despite all the velocity profiles have the same trend of those evaluated with the linear theory. Such an energy dumping is uniformly distributed along the water column due to the fact that the vegetation is almost emergent.

Following this interpretation of the results, more tests were carried out by focusing the attention on the wave dumping due to the presence of the canopy. The tests performed have been characterized by a constant water depth equal to $\mathrm{h}=21 \mathrm{~cm}$, wave period $\mathrm{T}$ included between 0.49 and $0.91 \mathrm{~s}$ and incident wave height $\mathrm{H} 1$ in between $2.3 \mathrm{~cm}$ and $4.8 \mathrm{~cm}$. All the tests were performed under conditions of intermediate water depth and only two tests were carried out in deep water.

The wave heights measured at the two probes ( $\mathrm{H} 1$ e $\mathrm{H} 2$ ), and the relative wave dumping $\Delta \mathrm{H}=\mathrm{H} 1$ $\mathrm{H} 2$, were correlated with the other variables recognized as significant of the present phenomenon, like the period $\mathrm{T}$, the wave length $\mathrm{L}$, the water depth $\mathrm{h}$ and the meadow length $\mathrm{lp}$. Some dimensionless parameters were used by applying the dimensional analysis. More in details, such parameters are: $\mathrm{h} / \mathrm{L}$, $\Delta \mathrm{H} / \mathrm{lp}, \mathrm{H} 1 / \mathrm{h}$.

The results show a significant wave height and energy reduction due to the interaction between the wave induced flow and the canopy. In particular, the wave height dumping increases when the incident wave height increases and when the ratio between the water depth $\mathrm{h}$ and the wave length $\mathrm{L}$ decreases, as it is shown in Fig. 9.

The wave height dumping reduction with the accretion of the ratio $\mathrm{h} / \mathrm{L}$ can be explained if we consider that such accretion corresponds to a less penetration of wave motion within the water column, which causes a less interaction between the wave induced flow and the plants. Moreover, the resulting accretion of wave height dumping, when the incident wave height increases as well, as expected suggests a nonlinearity of such a dumping phenomenon along the canopy.

The results analyzed in the present work are qualitatively in agreement with the outcomes of Mendez and Losada (2004) and Augustin et al. (2009), although the waves height reductions are not equal. Such difference can be reasonably explained by the different conditions related to the water depth, the leaves submergence, the shape, density and flexibility of the plants. 
(a) Without plants: $H_{i}=3.5 \mathrm{~cm} ; T=0.67 \mathrm{~s}$

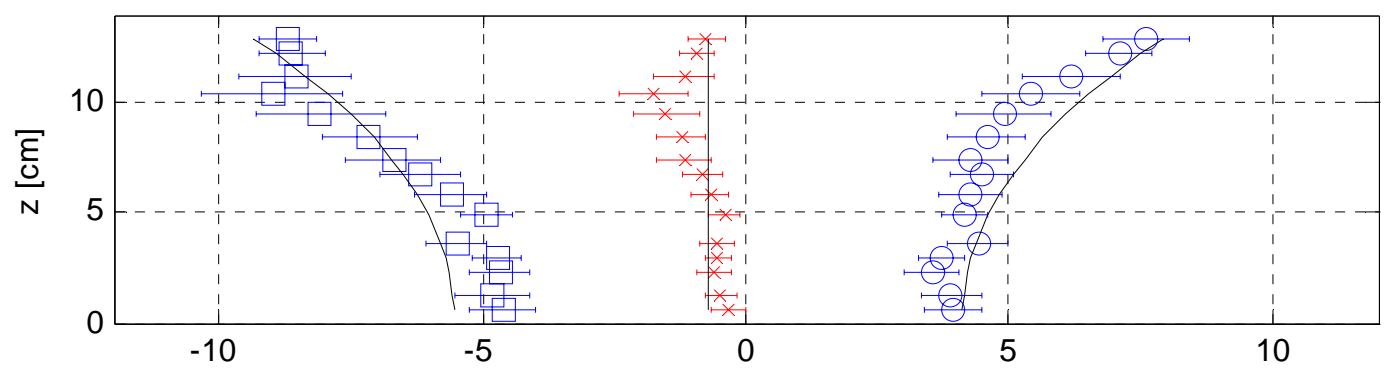

(b) Without plants: $H_{i}=3.2 \mathrm{~cm} ; \mathrm{T}=0.90 \mathrm{~s}$

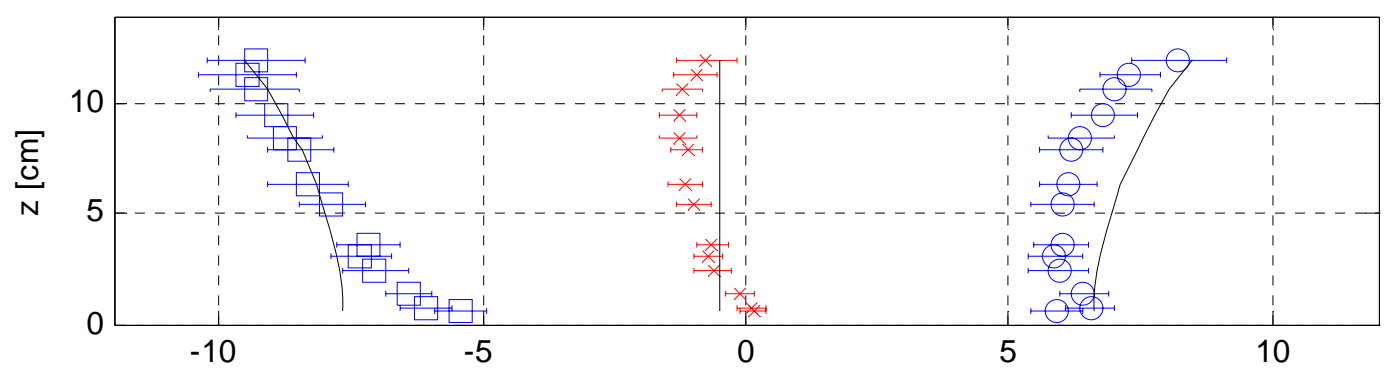

(c) With plants: $H_{i}=3.2 \mathrm{~cm} ; T=0.62 \mathrm{~s}$

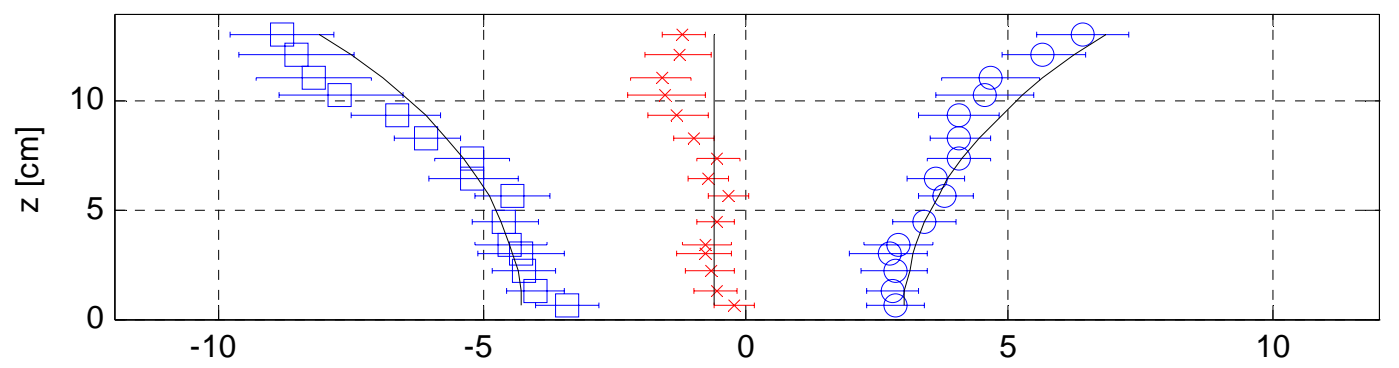

(d) With plants: $H_{i}=4.4 \mathrm{~cm} ; \mathrm{T}=0.74 \mathrm{~s}$

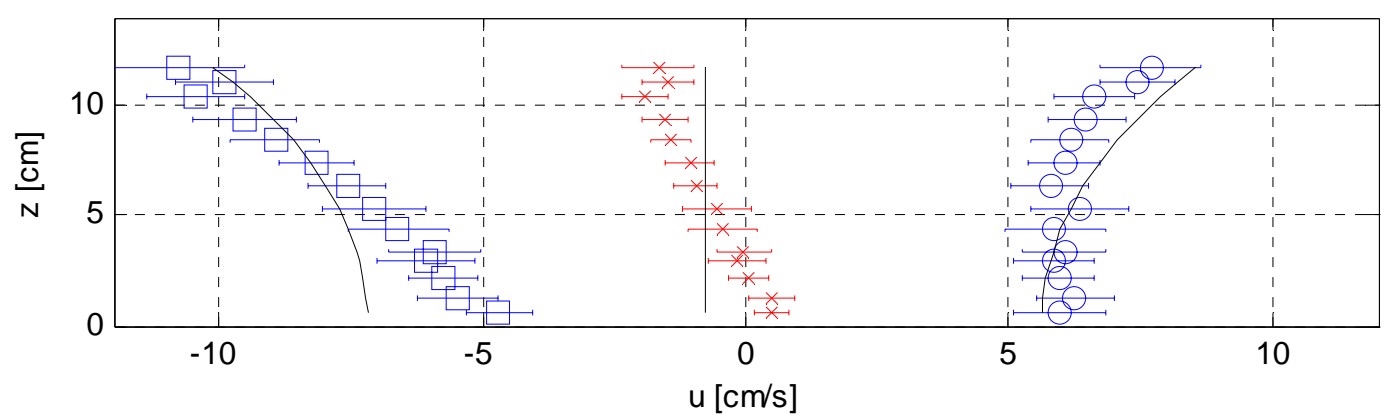

Figure 8. Maximum ( () , minimum $(\square)$ and average $(x)$ velocity profiles measured at the section $x=2.65 \mathrm{~m}$ from the wave maker. The confidence intervals of the measurements are also shown together with the velocity profiles derived from the linear wave theory. 


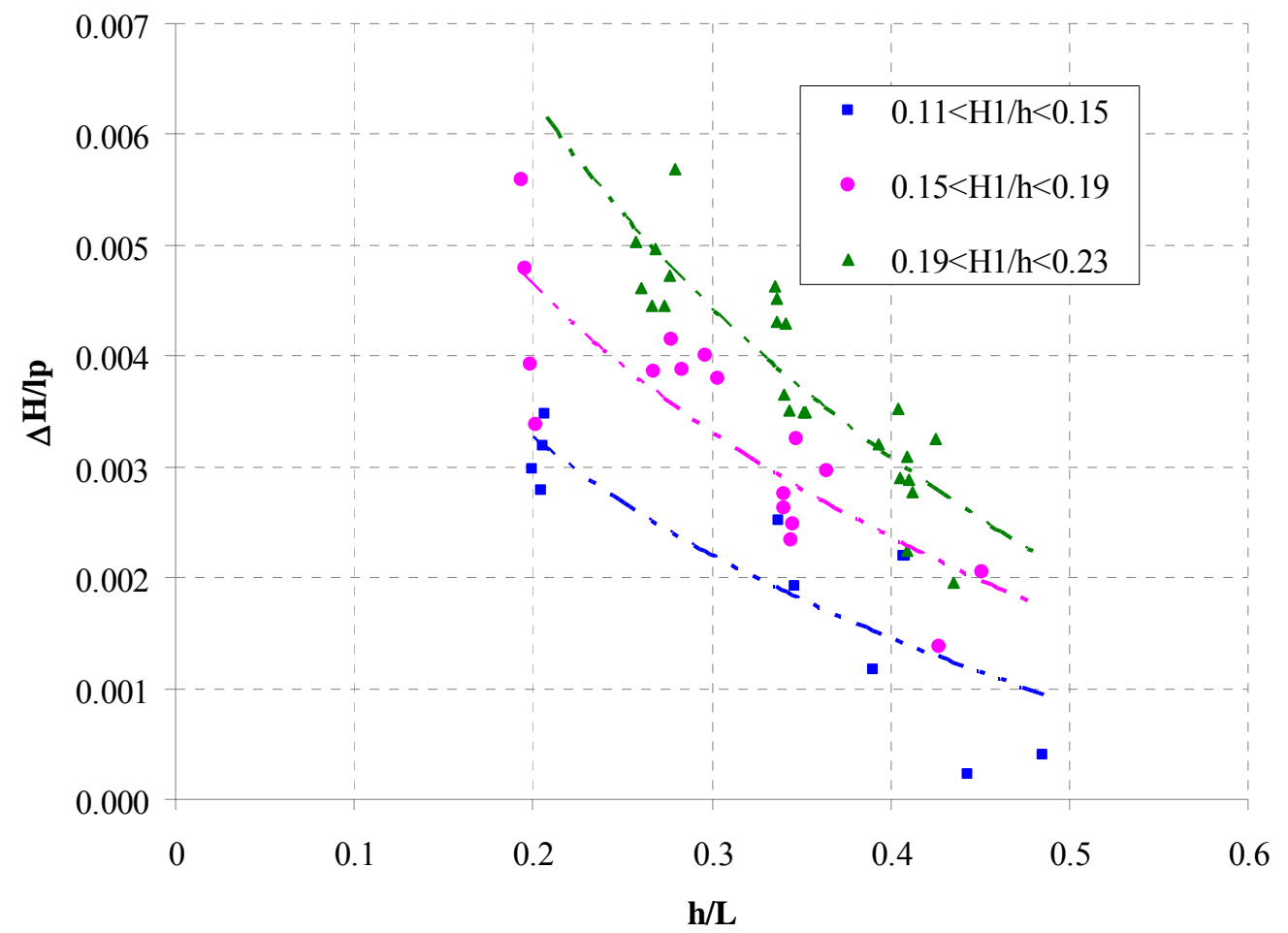

Figure 9. Wave dumping for meadow length unit versus the ratio between water depth and wave length. Three different curves are shown which are functions of the ratio between the incident wave height and the water depth.

For this reason a comparison was effected with some theories in the literature. In particular, the formulation first proposed by Dalrymple et. al (1984) and revised by Mendez and Losada (2004) suggests that the analytical dumped wave height is given by:

$$
H_{\text {dumped }}=K_{v} H_{w m}
$$

In particular, the dumped wave height is related to the wave produced at the wave-maker $\left(H_{w m}\right)$ by a coefficient $K_{v}$, which is function of the distance along the canopy $s$ :

$$
K_{v}=\frac{1}{1+\beta s}
$$

where

$$
\beta=\frac{4}{9 \pi} C_{D} b_{v} N H_{w m} k \frac{\sinh ^{3} k \alpha h+3 \sinh k \alpha h}{(\sinh 2 k h+2 k h) \sinh k h}
$$

in which $k$ is the wave number; $b_{v}$ is the plant area per unit height of each plant stands normal to the horizontal velocity $u ; N$ is the plant density; $h$ is the water depth; $\alpha h$ is the mean vegetation height and $C_{D}$ is the depth-averaged drag coefficient. It is important to stress that in this formula the uncertainty is correlated to the estimate of the drag coefficient, indeed such a coefficient is a function of the plant shape and flexibility, therefore it covers our lack of knowledge about the plant motion.

The drag coefficient so defined is often related to the Reynolds number, which can be written as: $R e=u_{c} b_{v} / v$, with $u_{c}$ the wave orbital velocity amplitude above the canopies and $v$ the kinetic viscosity. The relation available in literature to evaluate the drug coefficient $C_{D}$ as function of the Reynolds number for flexible plants in a wave field are presented in Table 1. It is important to point out that the formula of Kobayashi et. al. (1993) and Mendez et al. (1999) were both obtained on the basis of the experiment of Asano et al. (1988). 


\begin{tabular}{|c|c|c|}
\hline Formula & $\operatorname{Re}$ & $\mathrm{C}_{\mathrm{D}}$ \\
\hline Kobayashi et. al.(1993)* & $200-15500$ & $\mathrm{C}_{\mathrm{D}}=0.08+(2200 / \mathrm{Re})^{2.4}$ \\
\hline Mendez et al. (1999)* & $200-15500$ & $C_{D}=0.08+(2200 / R e)^{2.2}$ \\
\hline Bradley and Houser (2009) & $200-800$ & $\mathrm{C}_{\mathrm{D}}=(925 / \mathrm{Re})^{3.5}$ \\
\hline
\end{tabular}

The tests reported in the present paper are characterized by a Reynolds number in the range 40009500. The experiments of Asano et al. (1988) are characterized by Reynolds number comparable with those of the present experiments, while the data of Bradley and Houser (2009) are characterized by a narrow range of Reynolds number. For such a reason the formula of Bradley and Houser (2009) has not be considered in the following comparisons.

The experiments of Asano et al. (1988) were carried out with a meadow characterized by a density of the plant in the range $1110 \div 1490$ and by a ratio between the plants length and water depth in the range $0.48 \div 0.55$.

On the basis of the new data collected in the present experiments, a new relation between the drug coefficient and the Reynolds number is proposed:

$$
C_{D}=(2100 / \mathrm{Re})^{1.7}
$$

Fig. 10 reports the experimental data of Asano et al. (1988), those collected in the present experimental campaign, the relations proposed by Kobayashi et. al.(1993) and by Mendez et al. (1999), and those reported in Eq. (4).

The comparison between the data collected by Asano et al. (1988) with those evaluated in the present paper shows a good agreement in the in the range of Re between 3000 and 6000, while the difference between the two sets of data increase as the Reynolds number raises. Such behavior can be related to the different geometry of the meadow (plant density and ratio between the plants length and water depth) and also to the fact that in the present experiments each tuft is composed of three pairs of leaves with different length. More in details, as the Reynolds number increases the nonlinearities in the flow raise too, thus obtaining a stronger resistance effects.

\section{CONCLUSION}

An experimental investigation on the interaction between the flow induced by regular waves and the aquatic vegetation has been performed.

The first part of the work was focused on the identification of an artificial plant whose physical (flexibility, flotation, etc.) and dynamic (response to flow) characteristics could be comparable to the real one.

The second part of the work was devoted to the analysis of the mutual effects between the flow induced by waves and the leaves which form the canopy. Two different sets of experiments were carried out: the former focused on the evaluation of the effect in the velocity profile induced by the presence of the canopies; the latter related to the study of the wave damping due to the canopies. The results showed that the presence of the meadow does not change significantly the vertical distribution of the horizontal velocity, even though a significant reduction of wave height is observed. The intensity of such an attenuation seems to be related to the wave length and to the ratio between wave height and water depth. In particular the wave height dumping, for a unit length of meadow, increases when the product between the wave number $\mathrm{k}$ and the water depth $\mathrm{h}$ decreases, and it increases as the wave height raises. This result suggests the presence of non linearities of the wave dumping along the meadow.

The comparison of presented results with those available in literature showed that the drug coefficient could be affected by several characteristic of the meadow (plant density, ratio between the plants length and water depth and tuft structure). 


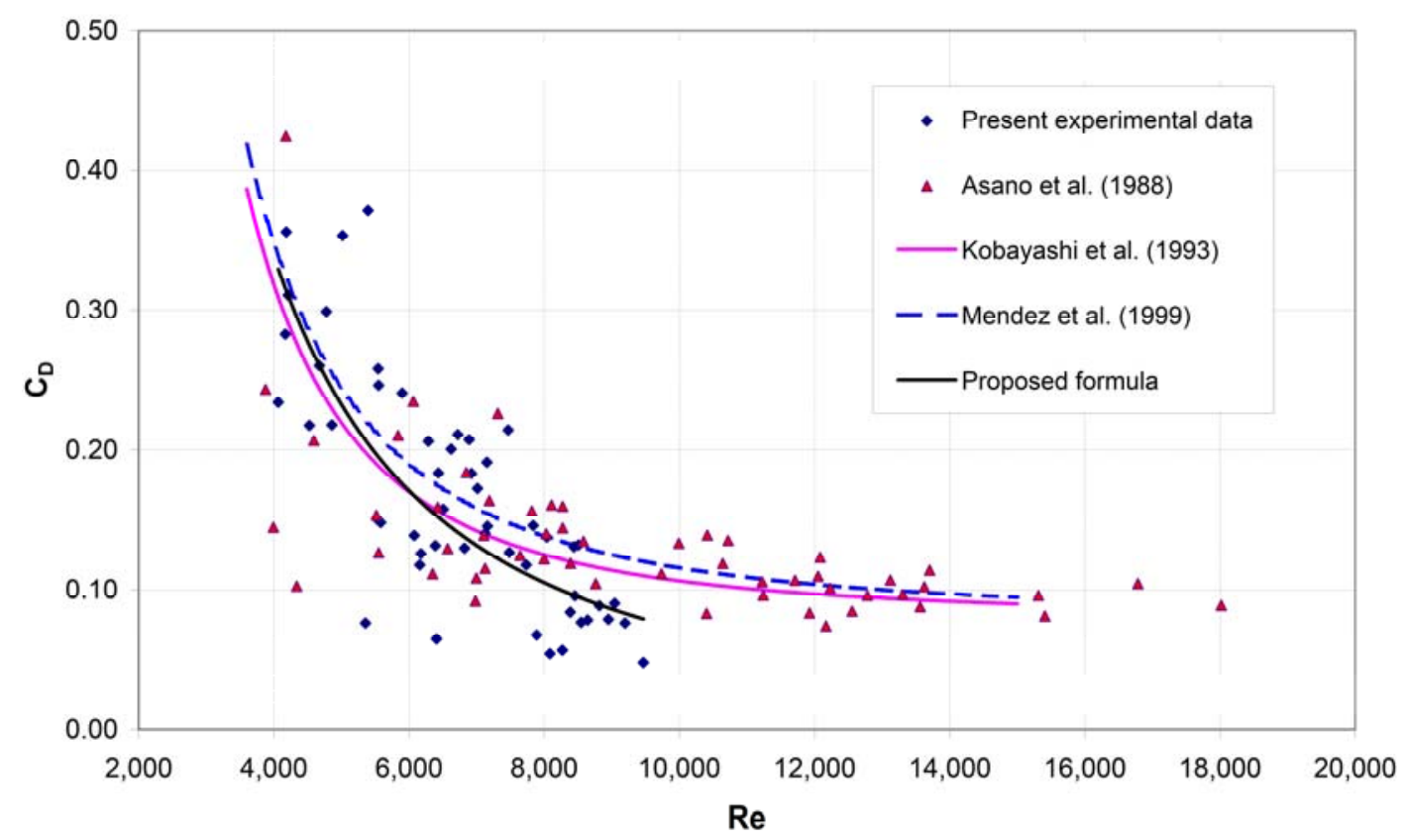

Figure 10. Drag coefficient as function of the Reynolds number.

\section{ACKNOWLEDGMENTS}

This work has been partly funded by: the EU project HYDRALAB-III (contract no. 0224411(RII3)) and by the Project PRIN 2008, titled: "Operative instruments for the estimate of coastal vulnerability in the presence of sandy beaches also in the presence of coastal structures", founded by the Italian Ministry of Education, University and Research.

\section{REFERNCES}

Asano, T., Tsutsui, S., and Sakai, T. 1988. Wave camping characteristics due to seaweed. Proceedings of $35^{\text {th }}$ Coastal Engineering Conference in Japan, (JSCE), 138-142.

Augustin, L. N., Irish, J. L., and Lynett, P. 2009. Laboratory and numerical studies of wave damping by emergent and near-emergent wetland vegetation. Coastal Engineering, 56, 332-340.

Boudouresque, C.F., Meinesz, A. 1982. Découverte de l'herbier de Posidonie. Cah. Parcnation. PortCros. Fr., A: 1-79.

Bradley, K., and Houser, C. 2009. Relative velocity of seagrass blades: implications for wave attenuation in low-energy environments. J. Geophys. Res., 114.

Ciraolo, G., Ferreri, G. B., and La Loggia, G. 2006. Flow resistance of Posidonia oceanica in shallow water. Journal of Hydraulic Research, 44 (2),189-202.

Ciraolo, G., and Ferreri, G. B. 2007. Log velocity profile and bottom displacement for a flow over a very flexible submerged canopy. Proc. of 32nd Congress of IAHR - Harmonizing the Demands of Art and Nature in Hydraulics, Venice, 1-6 July 2007.

Ciraolo, G., Ferreri, G. B., and La Loggia, G. 2008. Influence of Posidonia oceanica meadow density on flow resistance in shallow waters. Proc. of 2nd International Symposium on Shallow Flows, Hong Kong, China, 8-12 December.

Dalrymple R. A., Kirby, J.T., and Hwang, P.A. 1984. Wave diffraction due to areas of energy dissipation. J. of Waterway, Port, Coastal and Ocean Eng., 110 (1), 67-79.

Dean, R. G., and Dalrymple, R. A. 1992. Water wave mechanics for engineers and scientists. World Scientific.

Ghisalberti, M., and Nepf, H. 2002. Mixing layer and coherent structures in vegetated aquatic flow. $J$. Geophys. Res., 107 (C2),10.1029/2001JC000871.

Ghisalberti, M., and Nepf, H. 2005. Mass transfer in vegetated shear flow. Environmental Fluid Mech., 5(6), 527-551,10.1007/s10652-005-0419-1. 
Ghisalberti, M., and Nepf, H. 2006. The structure of the shear layer over rigid and flexible canopies. Environmental Fluid Mech., 6(3), 277-301,10.1007/s10652-006-0002-4.

Kobayashi, N., Raichle, A.W., and Asano, T., 1993.Wave attenuation by vegetation. J. Waterw. Port Coast. Ocean Eng. 119 (1), 30- 48.

Koch, E.W., Sanford, L.P., Chen, S., Shafer, D.J., and McKee, S. J. 2006. Waves in Seagrass Systems: Review and Technical Recommendations. Rep. ERDC TR-06-15. Engineering Research and Development Center US Army Corps of Engineers.

Lowe, R.J., Koseff, J.R., and Monismith, S.G. 2005. Oscillatory flow through submerged canopies: 1. Velocity structure. J. Geophys. Res.-Oceans, 110 (C10).

Mendez, F.J., Losada, I.J., and Losada, M.A., 1999. Hydrodynamics induced by wind waves in a vegetation field. J. Geophys. Res. 104 (C8), 18383-18396.

Mendez, F.J, and Losada, I. J. 2004. An empirical model to estimate the propagation of random breaking and non breaking waves over vegetation fields. Coastal Engineering, 51, 103-118. 